\title{
IMPORTANCE OF PLACEBO AND NOCEBO ACTION IN MECHANISMS OF ACUPUNCTURE EFFECTS
}

\author{
Dr. R. UMLAUF
}

Faculty Hospital Brno-Bohunice, Department of Acupuncture, Head Prim. MUDr. Richard Umlauf, CSc

The share of positive and negative psychic factors in the development, duration and therapy of painful conditions is very important, according to FINER, it is even decisive together with a constitution ground. Positive psychic factors are implemented most conspicuously in placebo application whose share in influencing the results is considered very pronounced by BEECHER. The following basic psychic factors can influence the pain intenzity in clinic :

1) Placebo and nocebo (nocere $=$ to harm)

2) Differential situational evaluating of pain stimuli

3 ) Specialized (e. g. purpose) tendencies

4 ) Changes of consciousness evoked artificially (e. g. by hypnosis) .

In pain provoked experimentally mainly placebo and the socalled factor of prejudice (bias factor) come into consideration.

The ability of a certain group of people to respond by required way at mere increase of attention, expectation of result or aimed instructions even without a specific effective performance has been termed placebo reactivity. The bearers of this property were given the term placebo reactors whose number in the normal population, according to EVANS, is about $35 \%$, in women after hysperectomy it can be elevated to as much as $65 \%$. However, the effects of psychic factors can be not only positive but also even negative (nocebo).

The term factor of prejudice (bias factor) is used by FINER for the designation of the influencing course or evaluating results of the experiment by an experimental person according to expectations and conviction of the persons controlling the experiment.

The evalution of pain is, however, made difficult by the influence of the whole complex of physiological and psychological factors on the pain perception. But it seems that the ideas of placebo action - particularly at analgesia - as a constant property of a certain personality have been surmounted. We cannot discount that in some people the pain tranquillizing can be achieved gradually by placebo performance. The so-called central controlling processes playing an unattainable role are probably responsible even for the changes in the concentra- 
tion of endogenous opiates, serotonin and other substances in the CNS. However, analgetic effects of placebo are usually lesser and substantially shorter than real analgetic performances.

Our experiments with influencing experimental pain in 223 experimental persons by acupuncture have shown that:

1) The using of placebo stimulation imitating both mechanical stimulation of acupuncture point $\mathrm{HE} \mathrm{GU}$ ( $\mathrm{Li} 4$ ) with an inserted needle by manual rotatory technique and the using of electrostimulation of acupuncture points HE GU and ZU SAN LI (S 36) through inserted needle with frequences of 200 and 600 impulses in a minute has shown no statistically demonstrable hypalgic effect if compared with control groups. At manual roratory placebo stimulation of point HE GU there occurred contralaterally even statistically demonstrable decrease of pain tolerance (on $5 \%$ level of significance) - that means the intervention was manifested as nocebo.

2) On the contrary, simple mechanical and electric stimulation of point HE GU through inserted needle provoked, in the course of 15 minutes, statistically significant hypalgesia (on $5 \%$ level of significance) and after 20 minutes of electrostimulation in the two points of $\mathrm{ZU}$ SAN LI through inserted needles with stimulation frequency of 200 and 600 impulses in a minute, there occurred, if compared with control groups, statistically significant hypalgesia (on $1 \%$ level of significance) both within and outside the segment. All the experiments were carried out in double-blind arrangement and under the same conditions (identical situation, instructions and simple reading of values from the device scale without verbal guiding).

KOMENDANTOVA et al. used 59 rabbits to study the influence of electroacupuncture (EAP) , morphine, phentanyl and combination of two latter with EAP on the changes of pain threshold. They have proved that the pain threshold was elevated by about $87 \%$ after EAP in points Li 4 and Si 18, while after electrostimulation outside acupuncture points under the identical conditions the pain threshold in experimental animals was elevated by $13 \%$ only.

ANDREJEV et al. have shown statistically in the experiments with rats that antistress effect of EAP in acupuncture point Gr 14 corresponds with antistress effect of Diazepam, while electrostimulation outside acupuncture point showed statistically significant influence neither on emotional reactivity and aggressivity of experimental animals.

Electrophysiological characteristics of acupuncture points also change if compared with placebo points (in indifferent vicinity) in dependence on the general condition of the organism, particularly of its nervous system. That has been proved by TKATCHENKO and ZORJAN's experiments who have found the increase of electric skin resistance by $73 \%$ in acupuncture points $\mathrm{L} 11$ and $\mathrm{H} 7$ in rats if compared with pldcebo points after the application of morphine in the dosis of $1 \mathrm{mg} / \mathrm{kg}$, by $132 \%$ with the dosis of $5 \mathrm{mg} / \mathrm{kg}$, while after the administration of Korazol ( 1 - / 4-hydroxyphenyl / 2-methylaminoethanol) in the dosis of $15 \mathrm{mg} / \mathrm{kg}$ its decrease by $33.4 \%$ and with the dosis of $25 \mathrm{mg} / \mathrm{kg}$ by $57.3 \%$. In placebo points electric skin resistance was unstable and changed in dependence on time.

Double-blind arrangement of experiments in any scientific research has also its great importance both for the proof of specific effects of acupuncture in comparison with placebopuncture, and for objectivization of acting of different variations of acupuncture in their mutual comparison (classic needle acupuncture, electroacupuncture, electropuncture, ase- 
rpuncture, sonopuncture, pharmacopuncture, thermopuncture, magnetopuncture, pressopuncture, and the like). In most of these variations of acupuncture, however, we shold have to prove in experiment their specific effects and, on the other hand, to find out the share of tactile stimulation and of placebo factors in their action to understand their real contribution.

Other works have shown the importance of intensity and method of stimulation at acupuncture. For example, MAO et al. have shown, in a group of 26 patients with chronic painful syndromes, that the intensive stimulation of acupuncture points, in comparison with their low sub-threshold stimulation at EAP, led not only to statistically significant clinical improvement (on $1 \%$ level of significance) but also to the increased contents of serotonin in thrombocytes (on $1 \%$ level of significance), which also gives evidence of the importance of central serotonin concentration and of its peripheral index in thrombocytes in the mechanism of analgetic effects of acupuncture.

LOBTCHENKO et al. studied and verified histologically the influence of different variations of electropuncture (EP) on the course of TBC process in four experimental groups of hamsters (totally 101 animals) with the following results : in the 1 st group they had used irritative variation of $\mathrm{EP}$ and $\mathrm{TBC}$ process detoriated statistically significantly (on $5 \%$ level of significance).

In the 2 nd group where indifferent variation of EP had been used, inconcpicuous, statistically unprovable improvement of TBC prosess occurred. In the 3 rd group where sedative variation of EP had been used, TBC process improved statistically significantly (on $5 \%$ level). The results in three ranks of the 4 th experimental group have shown that, for instance, in the $3 \mathrm{rd}$ rank where infected animals had been given $20000 \mathrm{u}$. of STM i. m. daily since the 2 nd day and since the 7 th day, moreover, sedative variation of $\mathrm{E}$. $\mathrm{P}$, the results were better statistically significantly (on $5 \%$ level of significance) than those in the $1 \mathrm{st}$ rank, where only STM in the same dosis had been administered to the experimental animals. Different variations of EP were used in points $\mathrm{Li} 4$ and Liv 14 in all the experimental groups.

But there are also reports doubting on the efficacy or specifity of acupuncture effects in comparison with placedo performances (e. g. HAIDER et al., GAW et al., GRUNDMANN, BAUST and STÜRZBACHER) .

The papers, demonstrations and discussions at the $3 \mathrm{rd}$ World Congress of Scientific Acupuncture ICMART 88 in Prague and particularly at the International Theoretical and Practical Seminar on Acupuncture in Brno at the end of May and at the beginning of June 1988 have shown the importance of experimental verification of acupuncture and related techniques in animals. Let me mention therefore some of the results achieved at the University of Veterinary Medicine in Brno during the last years :

1) Finding the evidence of objective existence of some acupuncture and ear points (better microzones) which can be used both for diagnosis and therapeutic reasons in small animals (ŠTILL). The basic, both morphological and functional, element of acupuncture - the acupuncture point - was investigated using :

-changes of skin impedance values (impedance $=$ relative skin resistance),

-distinct pressure sensitivity,

-some physiological changes occuring in the organism after the acupuncture point stimula- 
tion,

-therapeutic effects, following the acupuncture point stimulation.

702 dogs and 74 cats were used in 17 sigle experimental and clinical studies, out of which 90 dogs and 35 cats were in the control groups.

It was found that

-there were many points of decreased skin impedance in the course of the supposed acupuncture meridians mostly in the dog,

-there were more electrical active points than known acupuncture points (by 47\%),

-the localization of these points was relatively permanent,

-they conformed to the relevant acupuncture points of man in $79 \%$,

-considerable variability in the skin impedance values ranging from 4 to 70 Kiloohm was observed in these points,

-no specific reactions to the point detection occurred in clinical healthy dogs.

2 ) The exstence of ear active points (better microzones) was investigated in 449 dogs and 23 cats, 60 dogs and 8 cats were in the control group of healthy animals,

Results :

-Ear microzones were objectively detectable in the dog and the cat, both under the clinical and experimental conditions,

-ear microzones displayed the decrease of skin impedance and the increase of detection sensitivity,

-their localization was limited to certain ear area and was specific for the single pathologically altered or injured organs, body parts and functions,

-occurrence of these functional ear microzones was the highest in the case of acute inflammatory and generally painfull processes $(72-100 \%)$,

-painful pathological conditions (independently of the process type) were detectable in $90 \%$, painless pathological processes in $51 \%$, which is highly statistically significantly lower. The projection zones of organs in thoracical, abdominal, pelvis region pruritus cutanei, conjunctivitis, diseases of spine, front and hind limbs including joint projection were verified.

-In the case of chronic inflammatory processes occurred the functional ear microzones in 30 $-70 \%$, of compensated degenerative processes and non - aggressive tumors in $9-18 \%$ only.

-The ear microzones were found mostly bilaterally also in unilateral pathological processes, were larger in acute than in later stages and displayed certain dynamics in space and time.

In animals of control groups

-microzones specially sensitive to pressure were not found,

-microzones with lower skin impedance occurred locally and nonspecifically in $20-67 \%$.

The diagnostic possibilities of the abdominal cavity palpation in 89 and auriculodiagnosis in 78 dogs with clinical signs of gastritis acuta, gastroenteritis acuta and gastroenteritis acuta haemorrhagica (ŠTILL, KONRÁD) should be mentioned as an exampel : A significant difference in the causes of diagnosis in favour of auriculodiagnosis was confirmed by the statistical evaluation of the results. The best results were obtained when gastritis acuta was diagnosed : auriculodiagnosis was successful in $100 \%$ of the cases, in contrast to abdominal palpation which was successful in only $33.3 \%$ of the cases. The objectivity of detection, painfulness and the decrease of relative skin impedance were secured by the use of an 
atraumatic electrode with constant pressure.

3 ) The success rate of reanimation following the long-lasting apnoe caused by overdosis thiopental in 146 dogs and 51 cats and in a control group of healthy animals amounting 30 dogs and 27 cats (ŠTILL, KONRÁD) was $75-82 \%$. The acupuncture resuscitation has shown up to $100 \%$ results in clinically healthy dogs, whereas in animals affected with different diseases the success of intervention was smaller (77.47\%). The acupuncture points GV $26, \mathrm{H}$ 9 , P 9 and K 1 were used. Analogous by a stimulation of non-specific points in acral parts of limbs and placebo points in the snout region brought the success rate of $37-41 \%$ only.

Acupuncture reanimation was proved to be effective in all followed animal species and under all the various anesthesia. Needle acupuncture or acupressure stimulation of the points activated or sedated the altered respiration in the sense of its normalization, depending on the initial status of the organism. The success rate of the acupuncture resuscitation significantly decreased after the corticosteroid (prednisolon) application.

4) Acupuncture was a highly effective therapeutic method in the thoracolumbar diskopathia of the 1 st and 2 nd type in 97\% (ŠTILL). In the cases of $3 \mathrm{rd}$ and 4 th type its success rate was insufficient (36\%). Specially the analgetic effect of acupuncture was marked, but its influence on the disturbances of the motoric functions was distinct too. With the increase in the degree of spinal cord injury, the prognosis to a successful acupuncture tratment decreased.

As regards the final results of acupuncture therapy, the importance of each component of mechanism of its effects must not be ignored. However, sometimes the importance of the cocalled central controlling processes has been conceived as absolutely valid in little informed persons and particularly in opponents of acupuncture, for example, in PROKOP, DOTZAUER et al., who has considered acupuncture only suggestion, autosuggestion and placebo. However, how could they explain the above mentioned experimental results achieved just in animals? Then there must occur minimizing knowledge particularly of peripheral, spinal and subcortical mechanisms of acupuncture effects.

One of the causes of this condition is also represented by the circumstance that many publications about acupuncture are without more accurate methodological data, including the data about the used acupuncture variations (then the correct performance of acupuncture can be doubted), double-blind arrangement of experiments, statistical evaluation of the results in comparison with control groups, placebo performance and with results of other therapeutical methods (it is also the problem of evaluation criteria), not to mention nonscientific terminology and non-scientific explanation of the mechanisms of acupuncture effects. Nevertheless, the results of acupuncture research have shown the placebo, nocebo and other psychic factors have the same share in the final results of acupuncture therapy as in the results of any other treatment.

\section{Literature :}

1) Andreev, B. V., Vasiljev, J. N., Ignatov, J. D., Katchan, A. T., Bogdanov, N. N.: Vlijanie elektroakupunktury na projavlenie emocionalnogo stressa bolevogo geneza, Biull. EKsp. Biol. Med. 91 ( 1) , $18-20,1981$

2) Komendanotva, M. V., Zorjan, E. V., Jasnetsov, V. V. : Dejstvie morfina i fentanila v 
uslovijach elektrostimulacii biologiceski aktivnych tocek, Farmakol. Toksikol. 43 (1), $29-30,1980$

3 ) Lobtchenko, A. N., Starozinskaja, T. A., Zosimov, A. N. : Vlijanie elektropunktury na tecenie tuberkuloznoj infekcii v eksperimente, Probl. Tuberk. (9), 71-73, 1981

4) Mao, W., Ghia, J. N., Scott, D. S., Duncan, G. H., Gregg, J. M. : High versus low intensity acupuncture analgesia for treatment of chronic pain : effects on platelet serotonin, Pain, 8 (1980), $331-342$

5) Prokop, O., Dotzauer, G. : Die Akupunktur, Gustav Fischer Verlag, Stuttgart, New York, 1979

6) Still, J., Konrád, J. : A Comparison of the Diagnostic Possibilities of Abdominal Cavity Palpation and Ear Acupuncture in Dogs Suffering from Disorders in the Gastrointestinal Tract, Veter. Med. (Praha), 30, 1985 ( 7 ) , 425 - 431

7 ) Still, J., Konrád, J. : The Use of Acupuncture for Resusciation of Animals, Veter. Med. (Praha) , 30, 1985 ( 8) , $493-500$

8 ) Still, J. : Acupuncture in the Clinical Physiology and in the Clinic of Small Animals, Habilitation work, Brno, 1985

9) Tkatchenko, I. A., Zorjan, E. V. : Izmeneniẻ elektrokoznogo soprotivlenija v biologiceski aktivnych tockach kak pokazatel funkcionalnogo sostojanija organizma zivotnych, Farmakol. Toksikol. 43, (1) , 107 - 109, 1980

10) Umlauf, R. : Beeinflussung des experimentellen Schmerzes beim Menschen durch Akupunktur, K. F. Haug Verlag, Heidelberg, 1982

11) Umrauf, R. : Zu den Grundmechanismen der Akupunkturwirkung und Möglichkeiten ihrer Beeinflussung, K. F. Haug Verlag, Heidelberg, 1988

Author's address : MUDr. Richard Umlauf, CSc

Fügnerova 35

61300 Brno, Czechoslovakia 